\title{
MÉTODOS DE COLORAÇÃO DE ROESER (1972) - MODIFICADO - E KROPP (1972) VISANDO A SUBSTITUIÇÃO DO AZUL DE ASTRA POR AZUL DE ALCIÃO 8GS OU 8GX
}

\author{
Rebeca Luque ${ }^{1}$ \\ Hildeberto C. de Sousa ${ }^{2}$ \\ Jane Elizabeth Kraus ${ }^{3}$
}

Recebido em 14/12/95. Aceito em 2/6/96.

\begin{abstract}
RESUMO - (Métodos de coloração de Roeser (1972) - modificado - e Kropp (1972) visando a substituição do azul de astra por azul de alcião 8GS ou 8GX). Em folhas de Lychnophora ericoides. Coffea arabicu e Nymphaea mexicana foram testados métodos de coloração baseados em Roeser (1972) modificado e Kropp (1972), visando a substituiçāo do corante azul de astra por azul de alcião $8 \mathrm{GS}$ ou $8 \mathrm{GX}$. As amostras foram fixadas em FAA, desidratadas em série butílica terciária e incluídas em parafina. Os cortes histológicos transversais foram corados segundo diferentes baterias de coloração, modificadas quanto ao tipo de corante usado, diferenciador e série de desidratação. As lâminas permanentes foram preparadas com bálsamo-do-canadá sintético. Os resultados obtidos evidenciaram que o método de Roeser (1972) modificado é melhor que o de Kropp (1972), nas condições deste experimento. O azul de astra pode ser substituído por azul de alcião $8 \mathrm{GX}$ e a desidratação pode ser em série isopropílica ou etilica, sem grande diferença entre elas. São discutidos os resultados provenientes das diferentes colorações.
\end{abstract}

Palavras-chave: método de coloração, azul de astra. azul de alcião, fucsina básica, safranina, histologia vegetal

\begin{abstract}
Staining methods of modified Roeser (1972) and Kropp (1972), aiming at substituing the astra blue by alcian blue $8 \mathrm{GS}$ or $8 \mathrm{GX}$ ). Staining methods based on modified Roeser (1972) as well as that of Kropp (1972) were done with leaves of Lychnophora ericoides, Coffea arabica and Nymphaea mexicana aiming at substituing the astra blue stain by alcian blue 8GS or $8 \mathrm{GX}$. Samples were fixed in FAA, dehydrated in tert-butyl alcohol series and embedded in paraffin. The histological transversal sections were stained in different staining batteries, modified
\end{abstract}

Depart. de Biología. Facultad de Ciencias, Universidad de Los Andes, La Hechicera, Mérida 5 I0I, Venezuela

2 Depart. de Ciências Biológicas, Instituto de Ciências Exatas e Biológicas, Universidade Federal de Ouro Preto, Campus do Morro do Cruzeiro, CEP 35400-000 Ouro Preto, MG, Brasil

3 Depart. de Botânica, Instituto de Biociências, Universidade de São Paulo, C.P. 11461, CEP 05422-970 São Paulo, SP, Brasil 
according to the type of stains and differentiators, and the series of dehydration. Permanent slides were prepared with synthetic Canada balsam. The results obtained indicate that the modified Roeser method (1972) is better than that of Kropp (1972) under present experimental conditions. The astra blue can be substituted by alcian blue $8 \mathrm{GX}$ and dehydration can be isopropylic or ethylic, with little difference between them. The results obtained with the different staining techniques used are discussed.

Key words: staining method, astra blue, alcian blue, basic fuchsin, safranin, plant histology

\section{Introdução}

Os trabalhos de anatomia vegetal freqüentemente empregam métodos de dupla coloração para evidenciar as paredes celulares, conteúdos citoplasmáticos etc. Diferentes corantes e reagentes são utilizados, dependendo das estruturas a serem observadas e analisadas. Dentre os corantes empregados, merecem destaque o azul de astra e o azul de alcião, os quais possibilitam um excelente contraste, quando usados em conjunto com a safranina ou a fucsina básica.

O corante azul de astra é um complexo cobre-ftalocianina e, segundo Malzacher (1972), foi pela primeira vez utilizado para evidenciar mucopolissacarídeos ácidos na histologia humana por Pioch (1957). Malzacher (l.c.) também o utilizou para preparações totais de turbelários. Maácz \& Vágás (1961) introduziram este corante na microtécnica botânica em associação com a safranina e a auramina, visando a coloração diferenciada das paredes celulares celulósicas e lignificadas.

O azul de astra associado com a safranina foi empregado por Woessner (1970), Lindauer (1971), Bukatsch (1972), Kropp (1972) e Gerlach (1984), entre outros. Roeser (1972) foi pioneiro a utilizá-lo associado com a fucsina básica. Esse autor, entretanto, não definiu a concentração do corante, nem seu preparo.

O corante azul de alcião também é um complexo cobre-ftalocianina, que por sua vez tem sido amplamente empregado em microbiologia e histologia animal, e com especial ênfase na histopatologia humana. O seu uso foi introduzido por Steedeman (1950), seguido por Lison (1954), Adams (1956 apud Clark 1981), Adams \& Sloper (1956), Mowry $(1956,1960)$ e McManus \& Mowry (1960), para detecção citoquímica de glicosaminoglicanos livres e ligados a proteína nos tecidos animais. Também são importantes os trabalhos de Anderson \& Greiff (1964 apud Clark 1981), Wismar (1966), Mowry (1975 apud Clark 1981) e Tas (1977a, b). Nestes trabalhos, o corante foi empregado isoladamente ou associado com outros corantes ou reagentes, em especial com o ácido periódico e o reagente de Shiff (PAS).

Até hoje, o azul de alcião é amplamente usado em trabalhos de histologia animal, citando-se os de Gilloteaux et al. (1990), Decker \& Reale (1991), Niimura et al. (1991), Tanigawa et al. (1991), Rubio et al. (1991) e Jenkins et al. (1992).

Segundo Gahan (1984), embora usado por muitos anos nos estudos de mucopolissacarídeos nos tecidos animais, o azul de alcião tem sido relativamente pouco empregado para tecidos vegetais. Nesses materiais, os trabalhos de Benes̃ \& Uhlírová (1966 apud Gahan 1984) e Beneś (1968) são importantes, pois estudaram o sítio e o modo de 
coloração deste corante na parede celular. Mais recentemente, citam-se os trabalhos de Serrato-Valenti et al. (1992), Achar et al. (1993) e Srebotnik \& Messner (1994).

Em diversos trabalhos de anatomia vegetal, os métodos de coloração usados não são acompanhados das referências bibliográficas correspondentes, inviabilizando a obtenção das informações necessárias para a realização destes, bem como para a interpretação dos resultados obtidos. Além disso, vários dos métodos descritos para distinguir os tecidos vegetais não indicam corretamente o tipo e a concentração do corante usado e o preparo das soluções envolvidas, faltando, em outros, até a seqüência a ser seguida.

No Brasil, o método de coloração com azul de astra e fucsina básica (Roeser 1972, modificado) parece ter sido introduzido pelo Pe. Leopoldo Krieger da Universidade Federal de Juiz de Fora (MG) (Braga 1977) e tem sido muito usado desde Braga (1977 e 1982). Vários trabalhos utilizando esse método de coloração, com modificações ou não, têm deixado de citar a referência bibliográfica correspondente ou têm citado apenas o trabalho de Roeser (1972), o que inviabiliza a metodologia. Outros trabalhos têm empregado o azul de astra juntamente com a safranina e, por sua vez, não se referem aos trabalhos originais.

Após o levantamento bibliográfico, verificou-se que a solução do corante azul de astra usada no método de Roeser (1972) modificado tem sido preparada da mesma maneira que é indicada na metodologia de Maácz \& Vágás (1961), porém este autor não é citado.

Por outro lado, devido à dificuldade de se obter o corante azul de astra cujos índice de coloração ("Color Index" - CI) e fórmula estrutural são desconhecidos até o presente momento, este corante, muitas vezes, foi substituído pelo azul de alcião, porém de forma aleatória.

O objetivo do presente trabalho é analisar os resultados obtidos com os métodos de dupla coloração de Roeser (1972) modificado e Kropp (1972), que empregam azul de astra em associação com fucsina básica e safranina, respectivamente. Tal estudo visa também encontrar o melhor substituto do corante azul de astra empregando-se azul de alcião $8 \mathrm{GS}$ ou $8 \mathrm{GX}$.

\section{Material e métodos}

Para os testes de coloração foram selecionadas folhas das seguintes plantas: Lychnophora ericoides Mart. (xerófita), Coffea arabica L. (mesófita) e Nymphaea mexicana A. Gray (hidrófita).

Os corantes usados foram azul de astra ("astra blue" marca Merck, C.I. não indicado), azul de alcião ("alcian blue" 8GS marca Serva, C.I. 74240 e "alcian blue" 8 GX marca BDH, C.I. 74240), safranina ("safranin O" marca Aldrich, C.I. 50240) e fucsina básica ("basic fuchsin" marca BDH, C.I. 42510). O preparo dos corantes e diferenciadores está indicado no quadro 1 .

As diferentes amostras foram fixadas em FAA (formaldeído 37-40\%, ácido acético, álcool etílico 50\%, 1:1:18, v/v) segundo Johansen (1940). Foram desidratadas 
Quadro 1. Preparo dos corantes e diferenciadores.

\section{Preparo dos corantes}

Azul de astra

$2,0 \mathrm{~g}$ de ácido tartárico

$0,5 \mathrm{~g}$ do azul de astra

Dissolver o ácido tartárico em $80 \mathrm{ml}$ de água destilada, adicionar o azul de astra e completar com água destilada até $100 \mathrm{ml}$

\section{Azul de alcião 8GS}

Substituir o azul de astra por azul de alcião 8GS

\section{Azul de alcião 8GX}

Substituir o azul de astra por azul de alcião $8 \mathrm{GX}$

\section{Fucsina básica}

Dissolver $0,5 \mathrm{~g}$ de fucsina básica em $80 \mathrm{ml}$ de etanol $50 \%$ e completar até $100 \mathrm{ml}$ com etanol $50 \%$

\section{Safranina}

Dissolver $1 \mathrm{~g}$ de safranina em $80 \mathrm{ml}$ de água destilada e completar até $100 \mathrm{ml}$

Preparo dos diferenciadores

Etanol $80 \%$ acidificado

Solução-mãe: $100 \mathrm{ml}$ de etanol $70 \%+0,5 \mathrm{ml}$ de $\mathrm{HCl}$ concentrado

Diluir a solucão-mãe em etanol $80 \%$, ou seja, etanol $70 \%$ acidificado:etanol $80 \%, 1: 20$ (v/v)

Solução saturada de ácido pícrico

Colocar o ácido pícrico em $100 \mathrm{ml}$ de água destilada até começar a aparecer um depósito do mesmo, que não desaparece após agitação

em série butílica terciária (Johansen 1940) e incluídas em parafina (marca Reagen, P.F. $54-56^{\circ} \mathrm{C}$ ) com $8 \%$ de cera de abelha. Secções transversais com espessura entre 10$12 \mu \mathrm{m}$ foram realizadas em micrótomo rotativo (marca American Optical, modelo 820). Os cortes foram desparafinados com xilol (marca Merck) e hidratados em série etanólica segundo a carta de coloração descrita no quadro 2. Após os diferentes métodos de coloração empregados (vide quadro 2), foram preparadas lâminas histológicas permanentes com bálsamo-do-canadá sintético (Caedax, marca Merck) diluído em xilol $(1: 1, \mathrm{v} / \mathrm{v})$.

Em várias atividades, como fixação, desidratação e hidratação, além da relacionada com a coloração, o tempo foi padronizado, visando uma análise comparativa entre os diferentes métodos testados.

Os aspectos anatômicos mais relevantes foram registrados em microscópio óptico (marca Olympus-Vanox, modelo AHB-LB-1) acoplado a um sistema fotográfico (marca Olympus, modelo PM 10-35 AD-1), usando filtro azul LKB e filme Ektachrome 64 ASA (marca Kodak). Dos diapositivos foram feitas cópias de contacto. 


\section{Resultados}

O método de R I (Fig. 1-3) mostrou-se muito semelhante ao de R II (Fig. 4-6). O emprego da desidratação etílica (R II) levou, entretanto, a uma tênue coloração azul arroxeada, menos contrastante, quando comparado à desidratação isopropílica (R I). No caso de R III (Fig. 7-9), em que não foi empregada a solução saturada de ácido pícrico, observou-se um excesso de coloração por fucsina básica para quase todas as estruturas de Lychnophora, Coffea e Nymphaea.

Quando comparados os resultados obtidos em K I (Fig. 10-12) e II (Fig. 13-15) não foi verificada diferença entre eles, mostrando que os materiais podem ser desidratados em série isopropílica ou etílica. A ausência da passagem em etanol acidificado (K III) (Fig. 16-18) levou a um excesso da safranina em todos os materiais testados, mormente nas estruturas que contêm substâncias fenólicas.

Comparando-se o efeito da fucsina básica (R I e II) com o da safranina (K I e II), verificou-se que a primeira levou a uma coloração mais intensa.

O emprego do azul de alcião 8GS em R IV e V (Fig. 19 e 20, respectivamente) mostrou que esse corante não substituiu adequadamente o azul de astra, quando usado em mesma concentração e igual tempo de coloração. Verificou-se pouco contraste do corante, ou seja, ocorreu uma predominância da coloração por fucsina básica, levando inclusive a um resultado inferior ao obtido em R III, em que não ocorreu a diferenciação pela solução saturada de ácido pícrico. A pequena diferença entre estes resultados deve-se, possivelmente, à diferenciação dos corantes. Em K IV (Fig. 21) evidenciou-se que a associação deste corante com safranina foi pior, quando comparado com as baterias de Roeser, que empregaram a fucsina básica.

A análise das baterias de coloração empregando o azul de alcião $8 \mathrm{GX}$ em R VI e VII (Fig. 22 e 23, respectivamente) mostrou que esse corante pode substituir o azul de astra, dando um bom contraste de coloração em conjunto com a fucsina básica. A diferença na desidratação é a mesma observada em R I e II. O azul de alcião 8GX mostrou-se também muito eficiente nas colorações dos métodos de K V, VI e VII (Fig. 24,25 e 26, respectivamente). O emprego da solução saturada de ácido pícrico (K V) leva a um resultado melhor quando comparado ao obtido com etanol $80 \%$ acidificado (K VI e VII). A desidratação etílica (K VII) foi superior à isopropílica (K VI).

No método K VIII (Fig. 27), em que ocorreu o emprego do azul de astra e a solução de ácido pícrico, evidenciou-se um contraste relativamente melhor, quando comparado ao efeito do etanol acidificado (K I).

Nas observações histológicas em Lychnophora, onde a cutícula é bastante espessada, verificou-se que esta é mais evidenciada pelos métodos que empregaram a fucsina básica, do que quando se usou safranina. Neste material, quando do emprego da safranina, a coloração da cutícula só ficou bem evidenciada em K III (Fig. 16) na presença de excesso de corante. De um modo geral, os cloroplastos de todas as folhas também se mostram mais nítidos com fucsina básica, como pode ser visto em R I (Fig. 1-3), R II (Fig. 4-6) etc. Estas organelas também parecem ter ficado evidenciadas 
Quadro 2. Carta de coloração para o estudo comparativo dos métodos de Roeser (1972) modificado - R e Kropp (1972) - K - visando a substituição do azul de astra por azul de alcião 8GS ou 8GX.

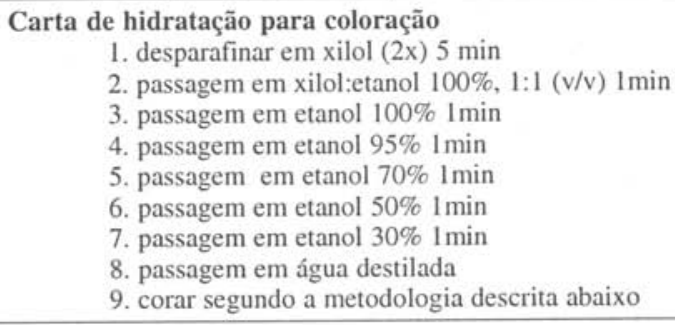

\section{R I (modificado)}

1. azul de astra $5 \mathrm{~min}$

2. lavagem em água destilada

3. fucsina básica $15 \mathrm{~min}$

4. passagem em água destilada

5. passagem rápida em solução saturada de ácido pícrico

6. passagem em isopropanol 70,80 e $100 \%$

\section{R III}

1. azul de astra 5 min

2. lavagem em água destilada

3. fucsina básica $15 \mathrm{~min}$

4. passagem em água destilada

5. passagem em isopropanol $50,70,90$ e $100 \%$

\section{R V}

1. azul de alcião 8 GS 5 min

2. lavagem em água destilada

3. fucsina básica $15 \mathrm{~min}$

4. passagem em água destilada

5. passagem rápida em etanol $80 \%$ acidificado

6. passagem em isopropanol 70,80 e $100 \%$

\section{R VII}

1. azul de alcião $8 \mathrm{GX} 5 \mathrm{~min}$

2. lavagem em água destilada

3. fucsina básica $15 \mathrm{~min}$

4. passagem em água destilada

5. passagem rápida em solução saturada de ácido pícrico

6. passagem em etanol $50,70,90$ e $100 \%$

\section{R II}

1. azul de astra $5 \mathrm{~min}$

2. lavagem em água destilada

3. fucsina básica $15 \mathrm{~min}$

4. passagem em água destilada

5. passagem rápida em solução saturada de ácido pícrico

6. passagem em etanol 50, 70, 90 e $100 \%$

\section{R IV}

1. azul de alcião $8 \mathrm{GS} 5 \mathrm{~min}$

2. lavagem em água destilada

3. fucsina básica $15 \mathrm{~min}$

4. passagem em água destilada

5. passagem rápida em solução saturada de ácido pícrico

6. passagem em isopropanol 70,80 e $100 \%$

\section{R VI}

1. azul de alciāo $8 \mathrm{GX} 5 \mathrm{~min}$

2. lavagem em água destilada

3. fucsina básica $15 \mathrm{~min}$

4. passagem em água destilada

5. passagem rápida em solução saturada de ácido pícrico

6. passagem em isopropanol 70, 80 e $100 \%$ 
K I (original)

1. azul de astra $5 \mathrm{~min}$

2. lavagem em água destilada

3. safranina $5 \mathrm{~min}$

4. passagem em água destilada

5. passagem rápida em etanol $80 \%$ acidificado

6. passagem em isopropanol $100 \%$

\section{K III}

1. azul de astra $5 \mathrm{~min}$

2. lavagem em água destilada

3. safranina $5 \mathrm{~min}$

4. passagem em água destilada

5. passagem em isopropanol 70,80 e $100 \%$

\section{K V}

1. azul de alcião $8 \mathrm{GX} 5 \mathrm{~min}$

2. lavagem em água destilada

3. safranina $5 \mathrm{~min}$

4. passagem em água destilada

5. passagem rápida em solução saturada de ácido pícrico

6. passagem em etanol $50.70,90$ e $100 \%$

\section{K VII}

1. azul de alcião $8 \mathrm{GX} 5 \mathrm{~min}$

2. lavagem em água destilada

3. safranina $5 \mathrm{~min}$

4. passagem em água destilada

5. passagem rápida em etanol $80 \%$ acidificado

6. passagem em etanol $100 \%$

\section{K II}

1. azul de astra $5 \mathrm{~min}$

2. lavagem em água destilada

3. safranina $5 \mathrm{~min}$

4. passagem em água destilada

5. passagem rápida em etanol $80 \%$ acidificado

6. passagem em etanol $100 \%$

\section{K IV}

1. azul de alcião $8 G S 5$ min

2. lavagem em água destilada

3. safranina $5 \mathrm{~min}$

4. passagem em água destilada

5. passagem rápida em etanol $80 \%$ acidificado

6. passagem em isopropanol $100 \%$

\section{K VI}

1. azul de alcião $8 \mathrm{GX} 5 \mathrm{~min}$

2. lavagem em água destilada

3. safranina $5 \mathrm{~min}$

4. passagem em água destilada

5. passagem rápida em etanol $80 \%$ acidificado

6. passagem em isopropanol $100 \%$

\section{K VIII}

1. azul de astra $5 \mathrm{~min}$

2. lavagem em água destilada

3. safranina $5 \mathrm{~min}$

4. passagem em água destilada

5. passagem rápida em solução saturada de ácido pícrico

6. passagem em isopropanol $50,70,90$ e $100 \%$

melhor nos métodos de K V (Fig. 24) e VIII (Fig. 27), baterias em que ocorreu a diferenciação com a solução de ácido pícrico.

Em resumo, nas condições deste experimento, notou-se que a passagem pela solução saturada de ácido pícrico ou pelo etanol $80 \%$ acidificado foi uma etapa importante para a diferenciação dos corantes, pois na ausência destes reagentes não se obteve um bom contraste. Como comentado anteriormente, a safranina empregada nos diversos métodos de Kropp mostrou uma resposta menos efetiva que a fucsina básica usada nos de Roeser, nas condições deste experimento. A desidratação isopropílica ou etílica não mostrou, de um modo geral, grandes diferenças.

\section{Discussão}

Os corantes azul de alcião e azul de astra são ftalocianinas, compostos cíclicos, que diferem das porfirinas metálicas pelo fato de grupos alquílicos nas posições 3 e 4 do anel pirrólico serem substituidos por grupos isoindólicos; os átomos que formam as 

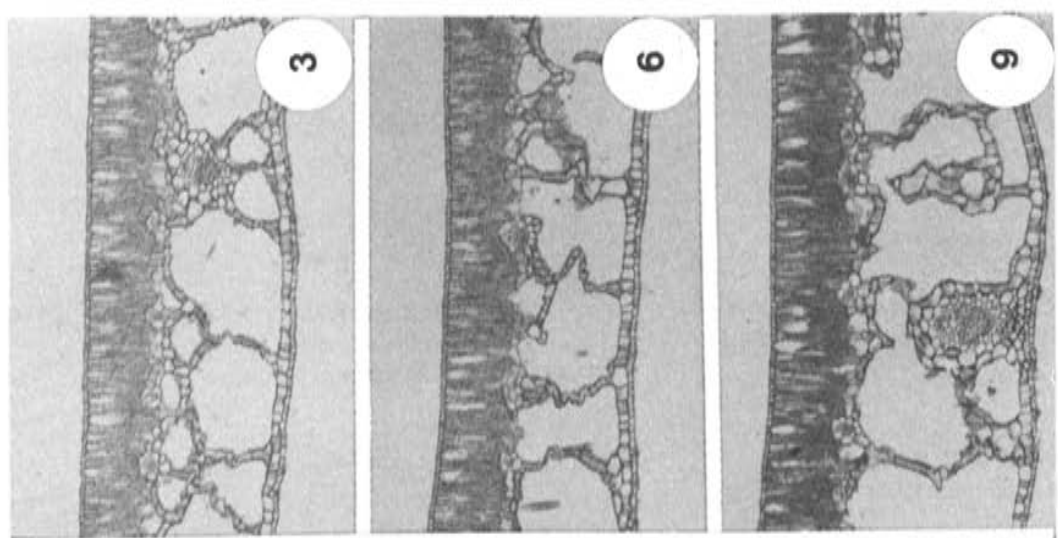

한

突栗

클

迅

ฐ $\simeq$

छैं

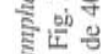

렁ㅇ

六突

ก

त善

造起

콜

난

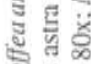
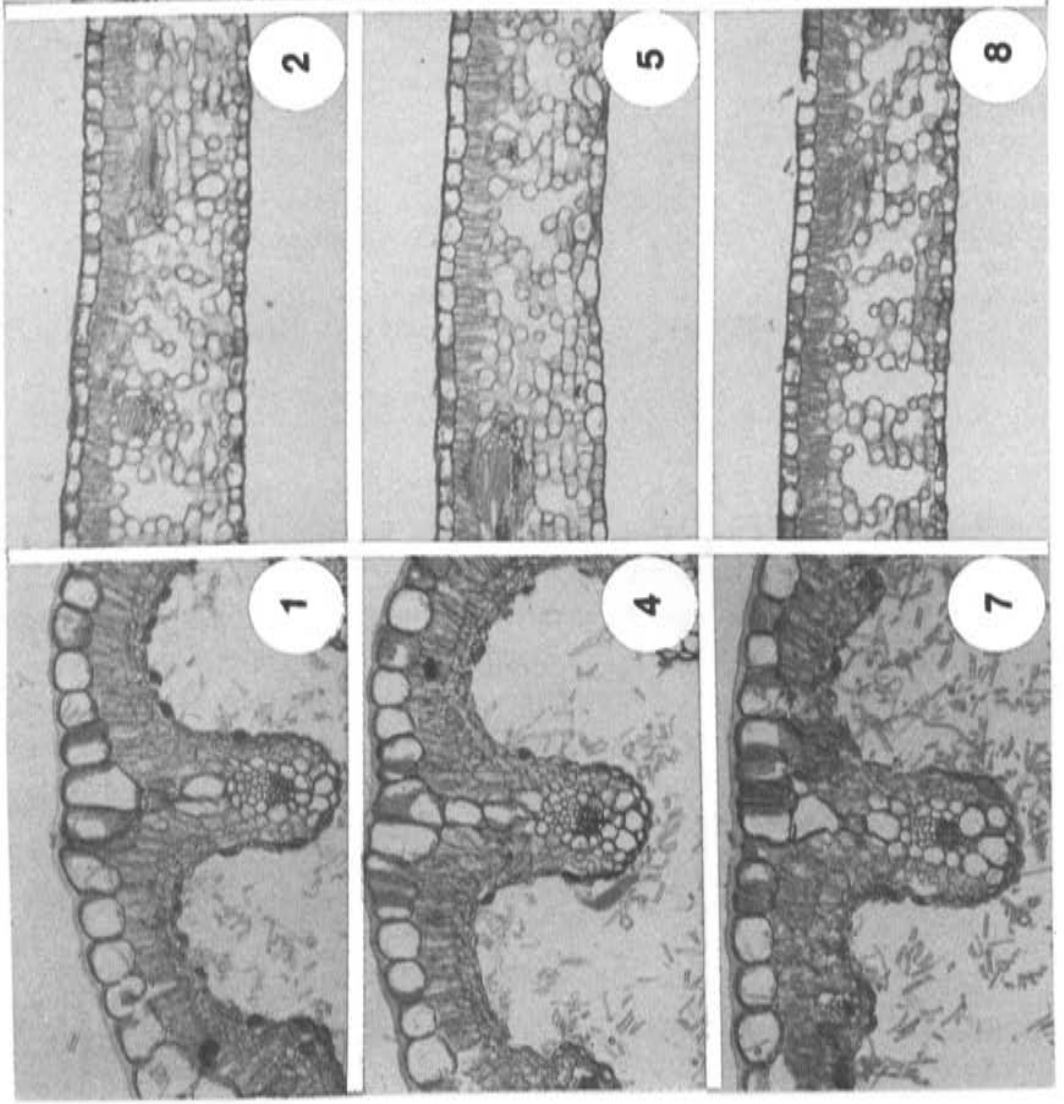

용

도롱

$\forall$.

- =

ㅂip $\simeq$

E。

है +

ํำ

这

혼

홀

인

त है

造尤

บ응

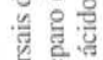

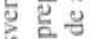

돌욜

蛅寻

댈

ช.

曾 寻

흥 틀

บ

요

플 है

는 연

iิ달

들

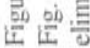



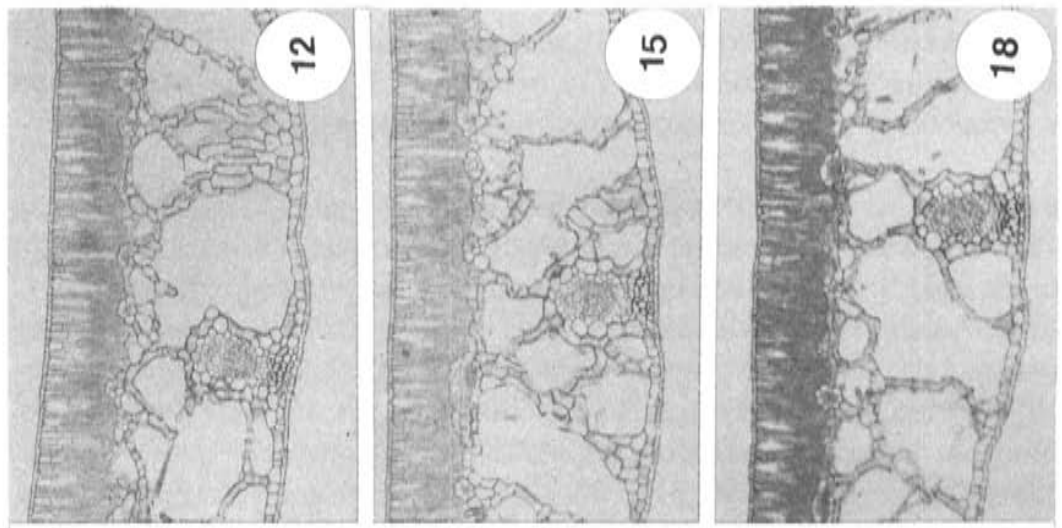

焉

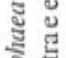

इ 厸

$\sum \frac{1}{3}$

$2 \overline{1}$

E

$\pm \equiv$

$=\frac{1}{0}$

ib $\frac{\infty}{1}$

近으

늘

కี

ษ

곤, 공

․ㅗㄹ올
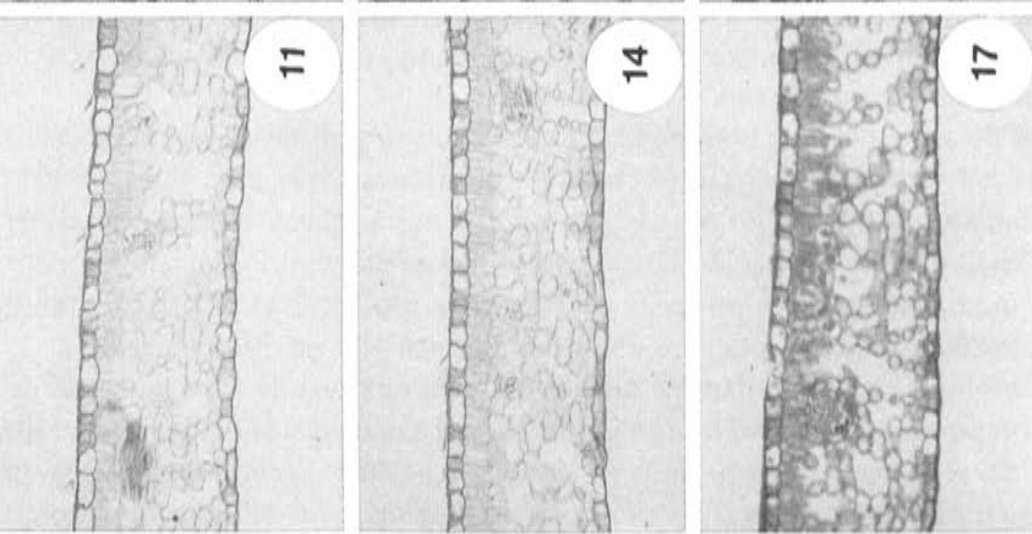

든

은

i) 르

近 然

ปํㅗ

릴

룽

$\approx \searrow$

능

हิ่

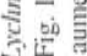

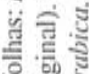

으. 밀

ป

늘 잉
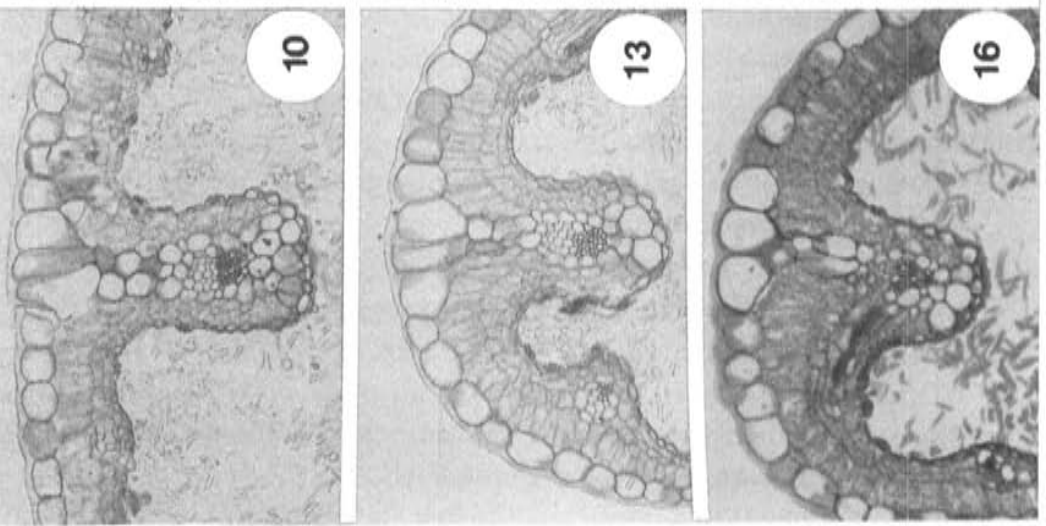

농

है

E

है

ช ल

它娄

है तี

응 $\simeq$

บํํㅇ

으응

몽

$\sum$ E

$\infty \frac{\infty}{2}$

dํㅡㅁ

그

离 몯

它这 
pontes de ligação são $-\mathrm{N}=$ em lugar de $-\mathrm{CH}=\mathrm{e}$ o átomo central metálico é usualmente $\mathrm{Cu}$ em lugar do $\mathrm{Fe}$, no caso da estrutura heme ou Mg, no caso da clorofila (Lillie 1990). Desse modo, era esperado que os resultados obtidos com o emprego de azul de alcião fossem semelhantes aos do azul de astra, no que se refere à afinidade pelas estruturas. Ainda, de acordo Horobin \& Goldstein (1972), todos os azuis de alcião e astra contêm os mesmos componentes azuis em cromatografia e em espectroscopia de infravermelho.

Entretanto, observou-se nítida diferença de coloração quando do emprego do azul de alcião $8 \mathrm{GS}$ ou $8 \mathrm{GX}$, sendo que somente este último pode substituir adequadamente o azul de astra, quando usado em mesma concentração e tempo de coloração. Schumacher \& Adam (1994) evidenciaram que ocorre variação nos resultados de coloração por azul de alcião, não somente pelas diferentes marcas empregadas, mas devido também a protocolos diferentes. No trabalho realizado, a grande diferença no efeito de coloração apresentada pelos corantes $8 \mathrm{GS}$ e $8 \mathrm{GX}$ é provavelmente devido a diferenças de códigos, marcas e/ou procedências, pois os protocolos seguidos nos experimentos foram os mesmos e os corantes apresentavam o mesmo C.I. No caso do azul de astra torna-se difícil propor algum esclarecimento, pois se desconhece o C.I. e a fórmula estrutural deste corante.

$\mathrm{O}$ azul de astra tem sido empregado em conjunto com diferentes corantes para distinguir as paredes celulares celulósicas das lignificadas. Maácz \& Vágás (1961) conjecturaram que a agregação do corante ocorre nos espaços intermicelares da celulose; obtiveram uma coloração azul para os componentes celulósicos das paredes celulares e uma coloração do amarelo ao vermelho tijolo (dada pela auramina e safranina) para as paredes lignificadas em diferentes estágios de diferenciação.

Em histologia vegetal o azul de alcião tem sido empregado para detecção de inúmeros compostos. Benes̃ \& Uhlírová (1966 apud Gahan 1984) e Benes̃ (1968) concluíram de seus estudos com variação de $\mathrm{pH}$, e usando diferentes métodos de digestão por pectinase, que o azul de alcião cora a pectina. Esta coloração provavelmente ocorre por ligações iônicas do corante com os grupos carboxílicos livres dos compostos pécticos. Este método, entretanto, poderia não corar pectinas metiladas ou esterificadas. Convém salientar que, para esses autores, a expressão azul de alcião foi usada no sentido amplo para os corantes ftalocianínicos solúveis em água. Nos seus experimentos empregaram tanto o azul de alcião ("alcian blue" marca Gurr) como o azul de astra ("astrablau" marca Chroma).

Chaubal et al. (1991) utilizaram esse corante para detectar a presença de glicoproteínas em tubos germinativos do fungo Puccinia sorghi e Pickett-Heaps et al. (1991) para a mucilagem de uma diatomácea (Adissonea crystallina).

Segundo Jeffree (1993), os polissacarídeos vegetais solúveis e ácidos (pectina, carboximetilcelulose etc.) são corados por corantes catiônicos como o azul de alcião $(8 \mathrm{GX})$ e os neutros (xiloglucanos, por exemplo) por PAS.

Schumacher \& Adam (1994) confirmaram que os glicosaminoglicanos são identificados nos tecidos por várias técnicas histoquímicas, incluindo coloração com azul de alcião e seus análogos. 
Assim, nos tecidos dos materiais estudados, pode-se inferir que o azul de astra ou o azul de alcião coraram os polissacarídeos, entre eles a celulose.

Segundo Berlyn \& Miksche (1976), a safranina pode corar paredes lignificadas ou cutinizadas e cromossomos, confirmando nossas observações nos materiais estudados, pois a cutícula, os cloroplastos e outras estruturas que não contêm ligninas mostraram-se coradas por safranina. Resultados semelhantes foram observados com a fucsina básica. Desse modo, pode-se propor que corantes básicos como a safranina e a fucsina básica evidenciam as substâncias fenólicas, entre elas a lignina e também têm afinidade por estruturas com composição diferente.

A afinidade dos corantes aniônicos ou catiônicos pelas várias estruturas ou tecidos é grandemente influenciada pelas cargas das amostras, e conseqüentemente, pelo $\mathrm{pH}$ da solução corante (Lillie 1990), explicando em parte as respostas diferentes provenientes do emprego de solução saturada de ácido pícrico ou etanol $80 \%$ com ácido clorídrico como diferenciador.

A análise global das metodologias de Kropp e Roeser testadas evidenciou que Roeser I, II (com azul de astra), VI e VII (com azul de alcião 8GX) foram as mais adequadas nas condições do experimento realizado. Entretanto, sabe-se, pelas informações contidas em livros de texto usuais de microtécnicas (e observações pessoais), que o tempo de coloração varia conforme o material e que depois de definido esse tempo podem ser obtidos bons resultados. Tal sugestão é válida para a metodologia de Kropp (1972), a qual pode ser empregada com resultados bem melhores aos obtidos nos experimentos realizados, quando do controle do tempo de coloração por safranina ou do diferenciador.

Concluindo, o trabalho realizado mostrou que o azul de astra pode ser substituído pelo azul de alcião 8GX, o qual apresentou propriedades semelhantes nos processos de coloração avaliados.

Os resultados obtidos evidenciaram, ainda, que o azul de alcião $8 \mathrm{GX}$, em associação com a fucsina básica, pode ser empregado para amostras vegetais oriundas de ambientes xérico, mésico e aquático.

Outra observação importante foi relativa ao uso do etanol, produto muito comum no Brasil, e, conseqüentemente, mais barato e mais fácil de ser adquirido, o qual pode substituir o isopropanol, sem grandes diferenças no processo de coloração.

\section{Agradecimentos}

Ao CNPq, pela bolsa de pesquisa concedida (Proc. $n^{2} 301776 / 83$ ). Aos Professores Doutores Berta Lange de Morretes, Liliana Forneris e Paulo Alberto Otto, pela tradução dos textos em alemão.

\section{Referências bibliográficas}

Achar, B.N.; Bhandari, J.M. \& Urs, H.G.V.G. 1993. A rapid safranin-wietal phthalocyanine double staining technique for plants. Biotech. \& Histochem. 68: 127-131. 
Luque et al.
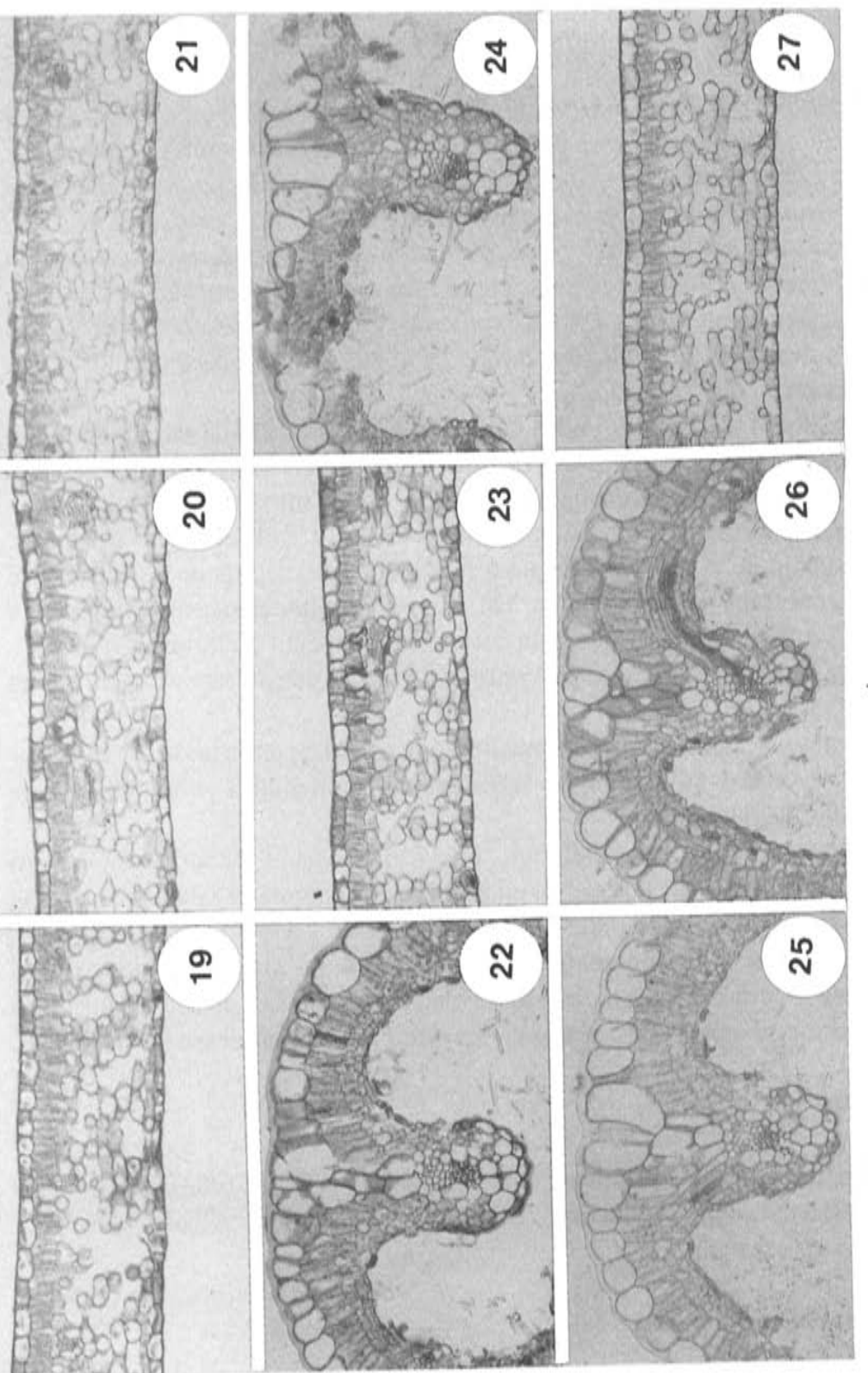

之爻总总

잉ํํ용

믈

医踏

กิํㅡㄹ

ชै

ป⿱一兀)

तิ่

点

प臣贺

ษึ่

옹 푱

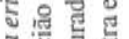

흘 랬

흘윰ำ

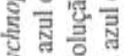

놀

ลำ

กิ่

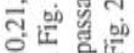

용ํํ

的包葛

둥

马्ّ

हี

与 $\overline{3}$.

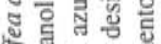

รั $>0$

U덩

ป

들

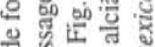

의

瓷嵒类之

战

फ้

읠 웜

勺ै है

융에

- D

解然

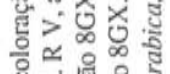

얼

भ

过江。

总语范

穴通齐妾

2든 $\simeq 4$

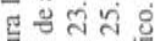

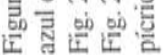


Adams, C.W.M. \& Sloper, J.C. 1956. The hypothalamic elaboration of posterior pituitary principles in man, the rat and dog; histochemical evidence derived from a performic acid-alcian blue reaction for cystine. J. Endocr. 13: 221-228.

Benes, K. 1968. On the stainability of plant cell walls with alcian blue. Biol. Plant. 10: 334-346.

Berlyn, G.P. \& Miksche, J.P. 1976. Botanical microtechnique and cytochemistry. Ames: Iowa State University.

Braga, M.M.N. 1977. Anatomia foliar de Bromeliaceae da Campina. Acta Amazonica 7: 1-74, suplemento.

Braga, M.M.N. 1982. Aspectos anatômicos das folhas de Virola Aubl. (Myristicaceae) como contribuição para sua Taxonomia. Manaus (AM): Instituto Nacional de Pesquisas da Amazônia e Fundação Universidade da Amazônia. Tese de Doutorado.

Bukatsch, F. 1972. Bemerkungen zur Doppelfärbung: Astrablau-Safranin. Mikrokosmos 61: 255 .

Chaubal, R.; Wilmot, V.A. \& Wynn, W.K. 1991. Visualization, adhesiveness, and cytochemistry of the extracellular matrix produced by urediniospore germ tubes of Puccinia sorghi. Can. J. Bot. 69:
2044-2054.

Clark, G. 1981. Staining procedures. $4^{\mathrm{a}}$ ed. Baltimore: Williams \& Wilkins,

Decker, B. \& Reale, E. 1991. The glomerular filtration barrier of the kidney in seven vertebrates classes: comparative morphological and histochemical observations. Eur. J. Basic and Appl. Histochem. 35: 15-36.

Gahan, P.B. 1984. Plant histochemistry and cytochemistry: an introduction. London: Academic Press.

Gerlach, D. 1984. Botanische Mikrotechnik: eine Einführung. Sttutgart: Georg Thieme Verlag.

Gilloteaux, J.; Pomerants, B.J., Kelly, T.R., Menu, R., Pelletier, G. \& Vanderhaeghen, J. J. 1990. Light and eletron microscopical immunolocalization of neuropeptide Y-containing nerves in the hamster gallbladder. Biol. Struct. Morphog. 3: 89-96.

Horobin, R.W. \& Goldstein, D.J. 1972. Impurities and staining characteristics of alcian blue samples. Histochem. J. 4: 391-399.

Jeffree, C.E. 1993. Immobilization of pectin, xyloglucan and other soluble plant polysaccharides on blotting membranes. New Phytol. 125: 695-706.

Jenkins, P.G.; Pulsford, A.L. \& Harris, J.E. 1992. Microscopy of the absorptive cells and gut-associated lymphoid tissue of the flounder Platichthys flesus. J. Mar. Biol. Assoc. U.K. 72: 553-567.

Johansen, D.A. 1940. Botanical microtechnique. New York: McGraw-Hill Book.

Kropp, U. 1972. Leitbündel. Mikrokosmos 61: 342-345.

Lillie, R.D. 1990. H. J. Conn's biological stains. 9." ed. St. Louis: Sigma Chemical.

Lindauer, R. 1971. Die Pflanzen-Epidermis: Isolierung, Färbung, Einschluss. Mikrokosmos 60: 170-178. Lison, L. 1954. Alcian blue 8G with chlorantine fast red 5B. A technic for selective staining of
mucopolysaccharides. Stain Technol. 29: 131-138. Maácz. G.J. \& Vágás, E. 1961. A new method for staining of cellulose and lignified cells-walls.
Mikroskopie 16: 40-43.

Malzacher, P. 1972. Eine neue Färbung für zoologische Totalpräparate: Astrablau-Boraxkarmin. Mikrokosmos 61: 181-182.

McManus, J.F.A. \& Mowry, R.W. 1960. Staining methods histological and histochemical. New York:
Harper \& Row,

Mowry, R.W. 1956. Alcian blue technics for the histochemical study of acidic carbohydrates. Proc. Histochem. Soc, 4: 407 ,

Mowry, R.W. 1960. Revised method producing improved coloration of acidic polyssacharides with alcian blue 8GX supplied currently. Proc. Histochem. Soc. 8: 323-324.

Niimura, S.; Fujisawa, N.; Sato, N.L. \& Ishida, K. 1991. Histochemical observations of proteins, polysaccharides and lipids in the oocytes and embryos of mastomys (Praomys natalensis) during the folliculogenesis and early development. Japan. J. Animal Reprod. 37: 65-70.

Pickett-Heaps, J.; Hill, D.R.A. \& Blaze, K.L. 1991. Active gliding motility in an araphid marine diatom, Ardissonea (formerly Synedra) crystallina. J. Phycol. 27: 718-725.

Pioch, W. 1957. Über die Darstellung saurer Mucopolysaccharide mit dem Kupferphthalocyaninfarbstoff 
Astrablau. Virchows Arch. 330: 337-346.

Roeser, K.R. 1972. Die Nadel der Schwarzkiefer - Massenproduckt und Kunstwerk der Natur. Mikrokosmos 61: 33-36.

Rubio, C.A.; Huang, C.B.; Porwit, A., Kock., Y. \& Stenling, R. 1991. Quantification of the colonic mucous cell population during protracted stress in rats. Stress Med. 7: 145-152.

Schumacher, U. \& Adam, E. 1994. Standardization of staining in glycosaminoglycan histochemistry: alcian blue, its analogues and diamine methods. Biotech. \& Histochem. 69: 18-24.

Serrato-Valenti, G.; Cornara, L., Lotito, S. \& Quagliotti, L. 1992. Seed coat structure and histochemistry of Abelmoschus esculentus: chalazal region and water entry. Ann. Bot. (Lond.) 69: 313-321.

Steesman, H.F. 1950. Alcian blue 8GS: a new stain for mucin. Q.J. Microsc. Sci. 91: 477-479.

Srebotnik, E. \& Messner, K. 1994. A simple method that uses differential staining and light microscopy to assess the selectivity of wood delignification by white rot fungi. App. Environ. Microbiol. 60: $1383-1386$.

Tanigawa, K.; Kawaguchi, M., Tanaka, O. \& Kato, Y. 1991. Skeletal malformations in rat offspring: longterm effect of maternal insulin-induced hypoglycemia during organogenesis. Diabetes 40: 1115 1121 .

Tas, J. 1977a. The alcian blue and combined alcian blue-safranin O staining of glycosaminoglicans studied in a model system and in mast cells. Histochem. J. 9: 205-230.

Tas, J. 1977b. Polyacrilamide films as a tool for investigating qualitative and quantitative aspects of the staining of glycosaminoglycans with basic dyes. Histochem. J. 9: 267-276.

Wismar, B.I. 1966. Quad-type stain for the simultaneous demonstration of intracellular and extracellular tissue components. Stain Technol. 41: 309-313.

Woessner, E. 1970. Astrablau-Safranin - noch einfacher. Botanische Mikropräparate mit geringstem Aufwand. Mikrokosmos 59: 31-32. 